Original Research Article

\title{
Association between serum sodium levels and selective serotonin reuptake inhibitors in patients with depression
}

\author{
Rajiv S.*, Meena K. Nandimath
}

Department of Pharmacology, Rajarajeswari Medical College, Bangalore, Karnataka, India

Received: 30 November 2016 Accepted: 24 December 2016

\section{*Correspondence to:}

Dr. Rajiv S.,

Email: rajiv_s_in@yahoo.com

Copyright: (C) the author(s), publisher and licensee Medip Academy. This is an openaccess article distributed under the terms of the Creative Commons Attribution NonCommercial License, which permits unrestricted noncommercial use, distribution, and reproduction in any medium, provided the original work is properly cited.

\begin{abstract}
Background: Hyponatremia is known to occur in patients on antidepressants. It is prevalent in approximately $2.5 \%$ of general hospital inpatient population, but can approach $11 \%$ among elderly patients. Relying only on symptoms for detecting hyponatremia may lead to under-diagnosing of hyponatremia; therefore, routine and frequent testing for serum sodium level is recommended, especially for older patients. This study is done to analyse the association between serum sodium levels and SSRIs in patients with depression.

Methods: A Prospective, Interventional study in the in-patient and out-patient department of Psychiatry Department was conducted for 3 months (August 2105 to October 2015). A total of 100 patients, aged over 18 years, diagnosed of depression, on SSRIs were analysed. Changes in serum sodium levels were observed at baseline and Week 4 of starting SSRI.

Results: A total of 100 patients were analyzed. 8 patients had serum sodium $\leq 130$ mmol-1, out of which 5 were females $(62.5 \%)$ and 3 were males $(37.5 \%)$. Prevalence of hyponatremia was more pronounced in patients aged $>60$ years (100\%), on Fluoxetine or Sertraline. Patients between 15 to 45 years of age did not experience any clinically significant hyponatremia at the fourth week after the therapy.

Conclusions: Our study indicates that users of SSRIs in elderly age group have a higher risk of developing hyponatremia. Clinicians evaluating elderly patients taking SSRIs are encouraged to monitor serum sodium if the patient presents with vague, nonspecific symptoms commonly associated with older age or depression to rule-out SIADH.
\end{abstract}

Keywords: Depression, Hyponatremia, SSRIs

\section{INTRODUCTION}

Hyponatremia is a disturbance in normal electrolyte concentrations, defined specifically as serum sodium below $136 \mathrm{mmol} / \mathrm{L}$.

It is prevalent in approximately $2.5 \%$ of the general hospital inpatient population, but can approach $11 \%$ prevalence among elderly patients. Symptoms of hyponatremia vary by severity and rapidity of onset. They involve central nervous system disturbances, but can mimic gastrointestinal problems and depression. ${ }^{1}$ If untreated, hyponatremia can lead to seizure, coma, and respiratory arrest when serum sodium levels fall below $120 \mathrm{mmol} / \mathrm{l}^{2}$
Worldwide, the population is aging, with more prominent demographic shifts occurring in developed nations with the best access to health care. Aged persons are susceptible to depression at a rate that exceeds that of their younger peers.

Hyponatremia has been associated with antidepressant use in the elderly. It is prompted by multiple classes of medications, and rates of hyponatremia are higher in elderly patients. As the elderly population grows worldwide, the potential for significant rates of otherwise avoidable morbidity and mortality due to the antidepressant-related hyponatremia experiences commensurate growth. 
Elderly patients are particularly at risk for hyponatremia in general, since many are taking diuretics for hypertension control, which some studies have shown to increase the risk of SSRI-associated hyponatremia. ${ }^{3}$

Loss of renal function, polypharmacy, dementia, and other conditions of advanced age can either exacerbate the severity of hyponatremia or mask its onset. Owing to renal functioning associated with aging, there is also an increased risk of elderly patients developing hyponatremia secondary to a syndrome of inappropriate antidiuretic hormone secretion. This is seen in approximately $10 \%$ of patients taking antidepressants, and is associated particularly with SSRIs and venlafaxine. $^{4}$

While hyponatremia can often be readily reversed once diagnosed, slow correction is necessary to rebalance sodium without triggering side effects such as central pontine myelinosis. ${ }^{5}$

Consideration of selective serotonin reuptake inhibitors (SSRIs) as one form of treatment for depression is a clinically sound option; however, awareness of a potential side effect rarely reported in the general population yet prevalent among the elderly is essential: SSRI-induced hyponatremia with associated mental status impairment. Through knowledge, early recognition, and prompt intervention strategies, the clinician will be prepared to manage hyponatremia and reverse its serious consequences.

\section{Drugs that increase ADH secretion centrally psychotropic agents}

Psychotropic agents have often been implicated in the cause of hyponatremia, including both antidepressants (tricyclics, selective serotonin reuptake inhibitors [SSRIs], and monoamine oxidase inhibitors) and antipsychotic drugs (phenothiazines and butyrophenones).

The mechanism by which these drugs cause hyponatremia is believed to be the development of SIADH. SSRIs are known to cause SIAD by stimulating AVP release from hypothalamus/neurohypophysis. ${ }^{6}$ This action of SSRI is particularly potentiated in the elderly due to their low osmotic threshold and osmotic response curve for sensation of thirst. Many elderly patients are on thiazide diuretics for hypertension or congestive cardiac failure $(\mathrm{CCF})$, and have sodium depletion. Increased thirst results in excessive water intake and causes water intoxication. However, it should be emphasized that low serum sodium levels in emotionally disturbed or psychotic patients may not be a direct consequence of these medications. Among the most frequent causes of hyponatremia in this population are the underlying psychosis its elfand the compulsive water drinking. Primary polydipsia is prominent in patients with psychosis, affecting nearly $7 \%$ of patients with schizophrenia. Exclusion of thyroid and adrenal insufficiency establishes the diagnosis of SIADH.

In addition to the underlying psychosis, the sensation of a dry mouth caused by psychotropic drugs (especially phenothiazines) may contribute to the increase in water intake. Thus, causality between psychotropic agents and hyponatremia was shown more persuasively with antidepressants and mainly with SSRIs, which cause hyponatremia more frequently than other antidepressant drugs. The incidence of hyponatremia caused by SSRIs varies widely from $0.5 \%$ to $32 \%$. In the majority of cases, hyponatremia occurs within the first few weeks of the onset of therapy, whereas the normonatremia is achieved within 2 weeks after drug withdrawal. Older age and concomitant use of diuretics are the most important risk factors for the development of hyponatremia associated with SSRIs.

Hyponatremia may be manifested with symptoms of headache, blurred vision, polydypsia, weakness, cramps, tremor, impaired gait, nausea, vomiting, seizure, confusion, and coma. The frequency of these manifestations are various among different populations. Most of these symptoms are non-specific and difficult to be distinguished from depression's symptoms or signs that may lead to miss management. Relying only on symptoms for detecting hyponatremia may lead to underdiagnosing this important complication of SSRI therapy; therefore, routine and frequent testing for serum sodium level is recommended specially for older patients.

The objective of the study was to determine the relationship between hyponatremia and antidepressants.

\section{METHODS}

Type of study was prospective and interventional study.

Place of study was the in-patient and out-patient department of Psychiatry at Rajarajeswari Medical College and Hospital.

Duration of study was 3 months (from August 2015 to October 2015).

Size of the sample was 100 patients.

\section{Inclusion criteria}

- Age: $>18$ years

- Sex: Both sex

Diagnosed case of depression on SSRIs with normal Sr. $\mathrm{Na}^{+}$levels.

\section{Exclusion criteria}

- Patients on diuretics

- Patients having chronic diarrhoea or vomiting. 
Demographic data and medication details were collected.

Serum sodium levels were observed at baseline and week 4 of starting SSRI.

\section{RESULTS}

From August 2015 through October 2015, 130 patients were enrolled but only 118 provided written informed consent to participate in this research study. Of these 118 patients, 18 men and women were excluded owing to the absence of a sodium level measurement at baseline or after initiation of treatment. Five women were excluded because they failed to meet the baseline sodium inclusion criteria.

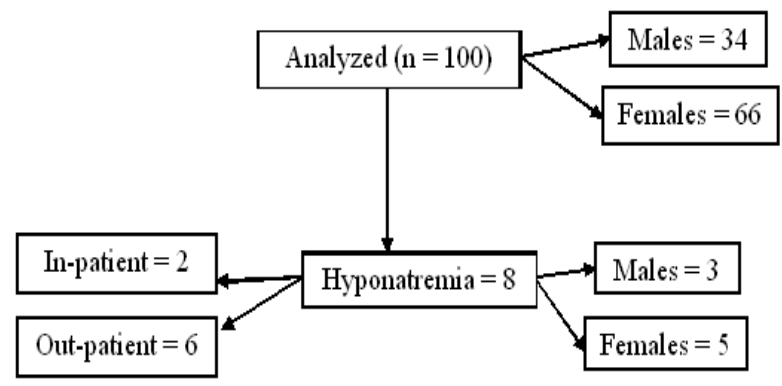

Figure 1: The methodology flowchart.

A complete medical, psychiatric, and medication history was obtained, and laboratory measures were assessed in all patients at the baseline visit. Plasma concentrations of sodium were determined before initiating SSRI therapy and after 4 weeks of treatment. Laboratory measures including levels of sodium were performed by the using an automated system.

Table 1: Age distribution.

\begin{tabular}{|ll|}
\hline Age (years) & No. of patients $(\%)$ \\
\hline$\leq 45$ & $50(50)$ \\
\hline $45-64$ & $30(30)$ \\
\hline$\geq 65$ & $20(20)$ \\
\hline Age $($ mean \pm SD) & $68 \pm 14$ \\
\hline
\end{tabular}

Table 2: Gender distribution.

\begin{tabular}{|ll|}
\hline Gender & No. of patients $(\%)$ \\
\hline Male & $34(34 \%)$ \\
\hline Female & $66(66 \%)$ \\
\hline
\end{tabular}

The medications and diseases known to be associated with hyponatraemia were recorded. Serum sodium levels of the patients are presented in Table 3. There was a significant decrease in serum sodium level of the older patients after first week of therapy with SSRI. A total of 12 patients had a serum sodium $\leq 130 \mathrm{mmol} \mathrm{l}^{-1}$. It should be mentioned that serum sodium level did not reach to hyponatremia in none of the younger patients i.e. $\mathrm{Na}<135$ $\mathrm{mEq} / 1$.

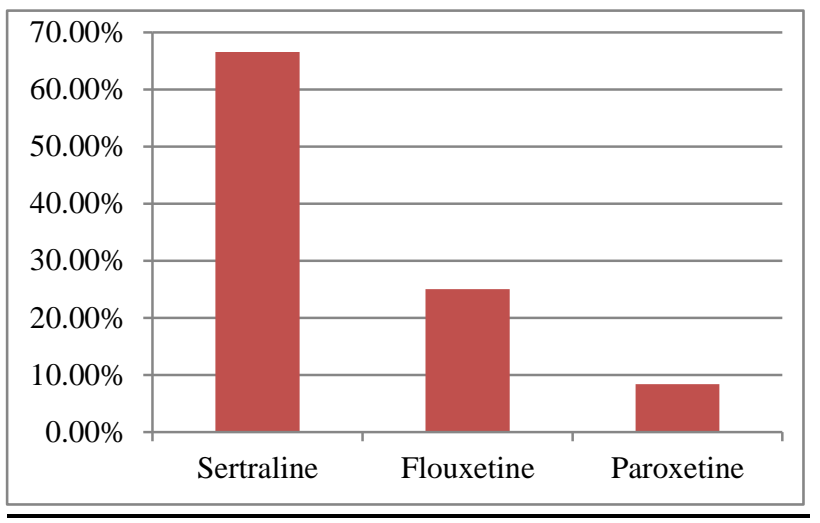

Figure 2: Different SSRIs used.

Table 3: Serum sodium levels.

\begin{tabular}{|llll|}
\hline $\begin{array}{l}\text { Sodium levels } \\
\text { before therapy } \\
(\mathbf{m m o l} / \mathbf{l})\end{array}$ & $\begin{array}{l}\text { No. of } \\
\text { patients } \\
(\%)\end{array}$ & $\begin{array}{l}\text { Sodium levels } \\
\text { after } 4 \text { weeks } \\
(\mathbf{m m o l} / \mathbf{l})\end{array}$ & $\begin{array}{l}\text { No. of } \\
\text { patients } \\
(\%)\end{array}$ \\
\hline $130-135$ & $25(25 \%)$ & $\leq 120$ & 0 \\
\hline $136-140$ & $58(58 \%)$ & $121-125$ & $8(8 \%)$ \\
\hline $141-145$ & $17(17 \%)$ & $126-130$ & $92(92 \%)$ \\
\hline
\end{tabular}

\section{Statistical analysis}

Descriptive statistics were used to summarize demographic, clinical, and baseline laboratory variables. All data are expressed as Mean \pm SD.

At the completion of the study, patients were classified into 1 of the following 2 groups: patients with hyponatremia (sodium level, $<135 \mathrm{mEq} / \mathrm{L}$ on $\geq 1$ occasions) or those who maintained normonatremia (sodium level, $\geq 135 \mathrm{mEq} / \mathrm{L}$ throughout the study).

Results are statistically not significant because of inadequate sample size, but hyponatremia observed in one patient is clinically significant. Hence, the prospective studies with large sample size are need.

\section{DISCUSSION}

The results of the present study showed a significant decrease in the serum sodium level of the patients after therapy in only 8 patients. However, hyponatremia only occurred in older patient aged >55 years and patients within 15 to 45 years of age did not experience a clinically significant decrease in the serum sodium level at the fourth week after the therapy. These results were consistent with other studies which have shown fluoxetine induced hyponatremia occurs in patients within 65 to 70 years age range but it is not frequent in young patients. 
Various studies have reported different frequencies of hyponatremia $(25 \%$ to $50 \%)$ in fluoxetine users. We found hyponatremia in $7 \%$ of the patients after the therapy. In other reports, in fluoxetine users, hyponatremia was more frequent at the second week of fluoxetine consumption, within the first to fourth week. Considering drug metabolism and different brands of drugs, these differences may be related to differences in the studied population.

Prior evidence for the association between antidepressants and hyponatraemia mainly stems from case reports. Another pharmacoepidemiological study including a control group has been conducted and showed that patients using fluoxetine had a higher risk for developing hyponatraemia compared with patients using no antidepressant drugs.

In an ambulatory geriatric population, Miller and coworkers found that $11 \%$ of the patients were hyponatraemic (serum sodium less than $135 \mathrm{mmol} \mathrm{l-}$ 1). ${ }^{1,18}$ Bouman and colleagues studied hyponatraemia in a group of older patients (mean age 77 year) admitted to a psychiatry ward. $^{19}$ They found the incidence of hyponatraemia (serum sodium less than $135 \mathrm{mmol} / \mathrm{l}$ ) to be $25 \%$ following the prescription of an SSRI.

It has been postulated that women are at greater risk of hyponatraemia, for which there may be several contributory factors. ${ }^{20}$ Female patients may have increased exposure to SSRIs because the incidence of appropriate indications is increased in the female population, and as described by Egberts and others, women are more likely to receive SSRIs than men in a community-based population, which may confound the association.

Limitation of this study is the sample size. The number of cases in this study was small, and therefore, we could not show a statistically significant difference. Unfortunately we were not able to determine the average time to onset of hyponatraemia because it was not possible to delineate the initial dates of therapy. However, according to the literature, hyponatraemia induced by antidepressants can occur from within 1 day to several months after the initiation of drug therapy. Liu and others described a median onset of 13 days. $^{21}$

Kirchner and coworkers also noted a wide range of time to detection from 1 to 253 days with a mean time to detect hyponatremia following SSRI initiation of approximately 3 weeks. ${ }^{22}$

In a prospective study of 14 cases of SSRI-induced hyponatraemia, the median time to onset was almost 14 days. $^{23}$

\section{Treatment and time course}

Treatment of hyponatremia depends on the patient's serum osmolality, fluid volume, and diagnosis, as well as classification of the hyponatremia. SSRI-induced hyponatremia often presents as isovolemic and is hypotonic in nature. ${ }^{24}$

This type of hyponatremia is initially treated by water restriction. Loop diuretics (e.g., intravenous furosemide 20-40 mg every 6-12 h) may be used to provide mild diuresis.

SIADH is one of the main causes of hyponatremia secondary to SSRIs. The treatments available for SSRIassociated hyponatremia secondary to SIADH include discontinuation of the causative agent and restriction of fluid intake to $1000-1500 \mathrm{~mL} / \mathrm{day}^{25}$

Severe, symptomatic hyponatremia may require aggressive diuresis with intravenous furosemide $1 \mathrm{mg} / \mathrm{kg}$ and electrolyte replacement with hypertonic saline $(\mathrm{NaCl}$ $3 \%){ }^{3,24,25}$ Oral furosemide $30-80 \mathrm{mg} / \mathrm{day}$ and sodium chloride supplementation may be an option. ${ }^{24}$

If sodium levels are corrected in a sudden manner, complications such as cerebral edema or central pontine demyelination may develop. It has therefore been suggested that serum sodium concentrations be corrected no faster than $0.5 \mathrm{mEq} / \mathrm{L} / \mathrm{h}$ and $8-12 \mathrm{mEq} / \mathrm{L}$ in the first 24 hours, with complete correction over 48-96 hours. ${ }^{2,26}$

Upon discontinuation of the SSRI, the time course of return to normal sodium concentrations has ranged from 48 hours to 6 weeks, with most cases resolving within 2 weeks. ${ }^{2}$ There is a paucity of published data on rechallenge with the same drug. ${ }^{27}$

Switching to another SSRI or switching to an agent from another therapeutic class, hyponatremia recurred in 3 of 6 cases when the suspected agent was restarted with complete correction over 48-96 hours. ${ }^{2,26,27}$

\section{Limitations}

The major limitation of the study is the small sample size.

The other limitation was that even though the association between SSRIs and low Serum Sodium levels was established in 8 patients, they could not be confirmed due to lack of follow up.

\section{CONCLUSION}

Our study indicates that users of SSRIs in elderly have a higher risk for developing In conclusion; our study indicates that users of SSRIs in comparison with other antidepressants have a higher risk for developing hyponatraemia. The elderly and those simultaneously using diuretics have the highest risk for this serious and potentially deadly adverse drug reaction. Physicians should be aware of SSRI-induced hyponatraemia in daily 
clinical practice, and we would advise that serum sodium concentrations are measured on a regular basis.

The results obtained from this prospective study provide a foundation for understanding the etiology and risk factors associated with SSRI-induced hyponatremia. Development and implementation of a rational plan for prescribing and safety monitoring of SSRIs in the aged should be based on an increased understanding of this common adverse event.

Funding: No funding sources

Conflict of interest: None declared

Ethical approval: The study was approved by the Institutional Ethics Committee

\section{REFERENCES}

1. Wright SK, Schroeter S. Hyponatremia as a complication of selective serotonin reuptake inhibitors. J Am Acad Nurse Pract. 2008;20:47-51.

2. Egger C, Muehlbacher M, Nickel M, Geretsegger C, Stuppaeck C. A review on hyponatremia associated with SSRIs, reboxetine and venlafaxine. Int $\mathrm{J}$ Psychiatry ClinPract. 2006;10:17-26.

3. Kirby D, Ames D. Hyponatraemia and selective serotonin re-uptake inhibitors in elderly patients. Int J Geriatr Psychiatry. 2001;16:484-93.

4. Kirby D, Harrigan S, Ames D. Hyponatraemia in elderly psychiatric patients treated with Selective Serotonin Reuptake Inhibitors and venlafaxine: A retrospective controlled study in an inpatient unit. Int $\mathrm{J}$ Geriatr Psychiatry. 2002;17:231-7.

5. Bogunovic $\mathrm{O}$, Sotelo J, Madhusoodanan S. Hyponatremia secondary to antidepressants. Psychiatric Annals. 2003;33:333-9.

6. David B. Mount fluids and electrolyte disturbances. In: Fauci L, editor. Harrison's principles of internal medicine. New York: McGraw-Hill; 2012:344-351.

7. Rosner MH. Severe hyponatremia associated with the combined use of thiazide diuretics and selective serotonin reuptake inhibitors. Am J Med Sci. 2004;327:109-11.

8. Kirby D, Harrigan S, Ames D. Hyponatremia in elderly psychiatric patients treated with selective serotonin reuptake inhibitors and venlafaxine: a retrospectivecontrolled study in an inpatient unit. Int $\mathbf{J}$ Geriatr Psychiatry. 2002;17:231-7.

9. Wilkinson TJ, Begg EJ, Winter AC, Sainsbury R. Incidence and risk factors For hyponatraemia following treatment with fluoxetine or paroxetine in elderly people. Br J Clin Pharmacol. 1999;47:211-7.

10. Fabian T, Amico J, Kroboth P. Paroxetine-induced hyponatremia inolder adults: a 12-week prospective study. Arch Intern Med. 2004;164:327-32.

11. Inaguma D, Kitagawa W, Hayashi H, Kanoh T, Kurata K, Kumon S. Three cases of severe hyponatremia under taking selective serotonin reuptake inhibitor (SSRI). Nippon Jinzo Gakkai Shi. 2000;42:644-8.
12. Schouten WE, Sepers JM. Hyponatraemia associated with the use of a selective serotonin-reuptake inhibitor in an older patient (letter). Age Ageing. 2001;30:94.

13. Flores G, Perez-Patrigeon S, Cobos-Ayala C, Vergara J. Severe symptomatic hyponatremia during citalopram therapy. A case report. BMC Nephrol. 2004;5:2.

14. Arinzon ZH, Lehman YA, Fidelman ZG, Krasnyansky II. Delayed recurrent SIADH associated with SSRIs. Ann Pharmacother. 2002;36:1175-7.

15. Guay D. Hyponatremia associated with selective serotonin reuptake inhibitors: clinical review. Consult Pharmacist. 2000;15:160-77.

16. Stedman CA, Begg EJ, Kennedy MA, Roberts R, Wilkinson TJ. Cytochrome P450 2D6 genotype does not predict SSRI (fluoxetine or paroxetine) induced hyponatremia. Hum Psychopharmacol. 2002;17:187-90.

17. Miller M, Hecker MS, Friedlander D, Carter JM. Apparent idiopathic hyponatremia in an ambulatory geriatric population. J Am Geriatr Soc. 1996;44:404-8.

18. Levinsky NG. Fluids and electrolytes. In: Isselbacher K, Braunwald E, editors. Harrison's Principles of Internal Medicine. New York: McGraw-Hill; 1994:242-253.

19. Bouman WP, Pinner G, Johnson H. Incidence of selective serotonin reuptake inhibitor (SSRI) induced hyponatraemia due to the syndrome of inappropriate antidiuretic hormone (SIADH) secretion in the elderly. Int J Geriatr Psychiatry. 1998;13:12-15.

20. Sharma H, Pompei P. Antidepressant-induced hyponatraemia in the aged. Avoidance and management strategies. Drugs Aging. 1996;8:430-5.

21. Liu BA, Mittmann N, Knowles SR, Shear NH. Hyponatremia and the syndrome of inappropriate secretion of antidiuretic hormone associated with the use of selective serotonin reuptake inhibitors: a review of spontaneous reports. Can Med Assoc J. 1996;155:519-27.

22. Kirchner V, Silver LE, Kelly CA. Selective serotonin reuptake inhibitors and hyponatraemia: review and proposed mechanisms in the elderly. J Psychopharmacol. 1998;12:396-400.

23. Wilkinson TJ, Begg EJ, Winter AC, Sainsbury R. Incidence and risk factors for hyponatraemia following treatment with fluoxetine or paroxetine in elderly people. Br J Clin Pharmacol. 1999;47:211-17.

24. Kraft M, Btaiche I, Sacks G, Kudsk K. Treatment of electrolyte disordersin adult patients in the intensive care unit. Am J Health Syst Pharm. 2005;62:1663-82.

25. Palm C, Pistrosch F, Herbig K, Gross P. Vasopressin antagonists as aquaretic agents for the treatment of hyponatremia. Am J Med. 2006;119(1):S87-92.

26. Palmer BF, Gates JR, Lader M. Causes and management of hyponatremia. Ann Pharmacother. 2003;37:1694-702.

Cite this article as: Rajiv S, Nandimath MK.

Association between serum sodium levels and selective serotonin reuptake inhibitors in patients with depression. Int J Basic Clin Pharmacol 2017;6:349-53. 